\title{
The effect of mature elephant bull introductions on ranging patterns of resident bulls: Phinda Private Game Reserve, South Africa
}

\author{
Heleen Druce, K. Pretorius, D. Druce and R. Slotow
}

\begin{abstract}
Druce, Heleen, K. Pretorius, D. Druce and R. Slotow. 2006. The effect of mature elephant bull introductions on ranging patterns of resident bulls: Phinda Private Game Reserve, South Africa. Koedoe 49(2): 77-84. Pretoria. ISSN 0075-6458.

Increasing popularity of wildlife viewing has resulted in a rapid increase in small, enclosed reserves in South Africa. The African elephant is one of the many species that has been reintroduced into these reserves for eco-tourism. These elephant populations were established as young $(<10$ years old) orphans from prior Kruger National Park culling operations. Consequently, this abnormal sex and age structure of these introduced populations has influenced their behavioural and spatial ecology. In Pilanesberg National Park, this abnormal behaviour was corrected by introducing older bulls and culling certain problem elephants. In July 2003, three older bulls (29-41 years old) were introduced into Phinda Private Game Reserve, KwaZulu-Natal, South Africa in order to normalise the bull age structure. These introduced bulls were monitored intensively after release, as was the resident bull population, both before and after introduction of the older bulls. The introduced bulls settled into restricted ranges separate from the family groups. All the resident bulls decreased their home ranges at first, with most increasing their home ranges a year later. The resident bulls' change in ranging patterns was due more to ecological factors than to the influence of the mature bull introduction. This study indicates that the introduction of older male elephants into small populations does not pose major risks or animal welfare concerns.
\end{abstract}

Key words: Loxodonta africana, adaptive management, movement patterns, kernel ranges, GIS.

Heleen Druce, D. Druce and R. Slotow $ه$ (slotow@ukzn.ac.za), Amarula Elephant Research Programme, School of Biological and Conservation Sciences, George Campbell Building, University of KwaZulu-Natal, Durban, 4041 South Africa; K. Pretorius, Phinda Private Game Reserve, KwaZulu-Natal, South Africa (kevinp@ccafrica.com).

\section{Introduction}

Wildlife viewing in protected areas as a form of recreation is steadily increasing in popularity. As a result, there has been a rapid increase in the number of small reserves $\left(<1000 \mathrm{~km}^{2}\right)$ during the last few years in South Africa (Druce et al. 2004; Slotow et al. 2005). Although some of these reserves have been developed to enhance biodiversity conservation, most of them exist purely for the eco-tourism industry. Tourism entails the reintroduction of valuable viewing species into these reserves regardless of the ecology and the sustainability of these and other species. The African elephant (Loxodonta africana) is one of the key species in the ecotourism industry. As a result, many state and private game reserves have reintroduced elephants, many of which were orphanedsurplus elephants originating from culling operations in Kruger National Park (Garaï et al. 2004; Slotow et al. 2005). As these small reserves are enclosed by electric fences which prevent any natural immigration \& emigration, they need to be actively managed (Slotow \& Van Dyk 2004; Slotow et al. 2005) to ensure that elephants can meet all of their ecological and social needs (Garaï et al. 2004).

The basic unit of elephant social organisation is the family group (Laws \& Parker 1968; Douglas-Hamilton 1973). Males born into 


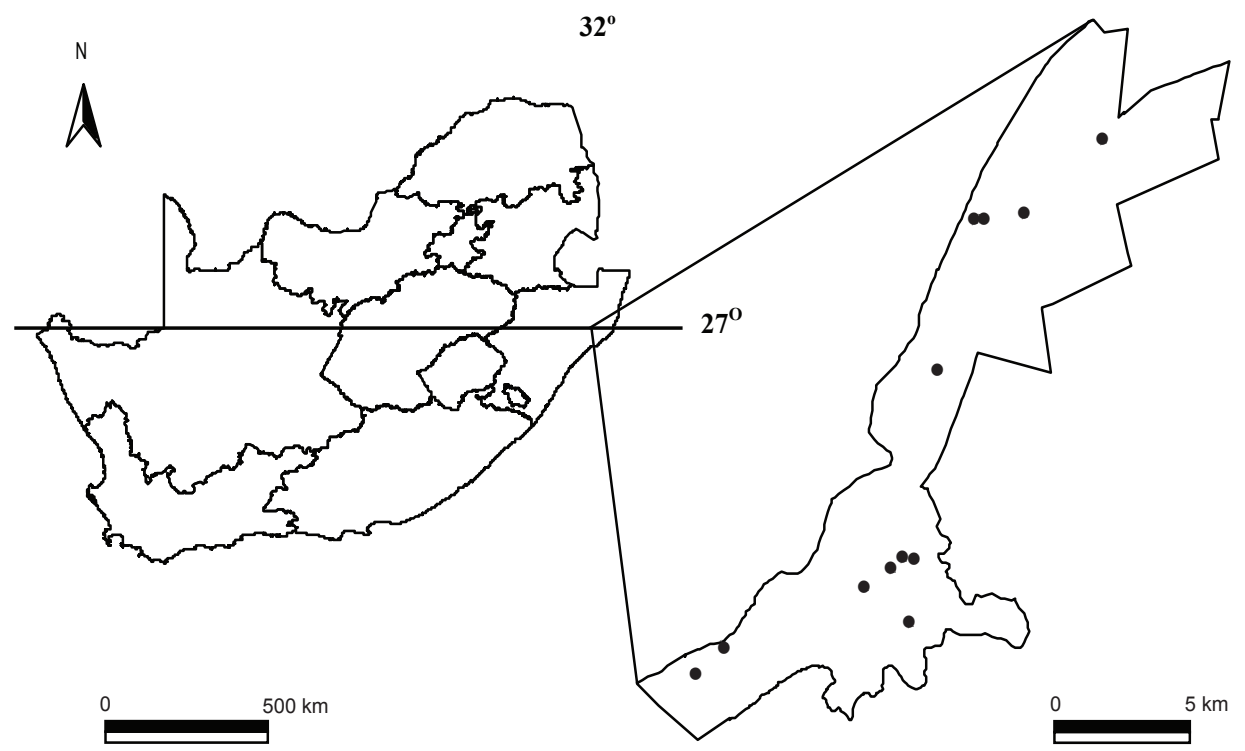

Fig. 1. Phinda Private Game Reserve. Black dots indicate the position of sites where artificial feed was provided during the winter of 2003.

the family group will leave the group or are forcibly ejected after reaching puberty, which is usually between the age of 14 and 17 years (Poole et al. 1984; Poole 1989) Within these bull groups male association is random and they do not form any long-term bonds with other individuals (Laws \& Parker 1968; Moss \& Poole 1983).

Phinda Private Game Reserve was established in 1991, with an area of approximately $150 \mathrm{~km}^{2}$ (Fig. 1). The core of Phinda's elephant population was introduced from Kruger National Park between 1992 and 1994. These elephants were orphans from prior Kruger culling operations, and because equipment to transport elephants was limited to animals shorter than $2 \mathrm{~m}$, all the individuals were young and within the same age class (approximately 10 years old or younger at introduction). During 1994, four adult elephants, two bulls and two cows (approximately 20-25 years of age) were introduced from Gonarezhou National Park, Zimbabwe. During June/July 2003, a total of 37 elephants of four different family groups were translocated from Phinda to other reserves. Three older bulls (see below) from Sabi-Sand in Limpopo Province, South Africa were introduced into Phinda between July and August 2003. In July 2004, the total elephant population comprised 78 individuals, including 19 adult bulls.

Prior to the bull introduction in 2003, Phinda only had one 36-year-old bull (bull code PH1) and 15 young bulls aged between 15 and 26 that were independent of the breeding herds. This age structure was unnatural because of the large proportion of young males of approximately the same age. A natural population structure should have individuals spread through the different age groups. Because the oldest resident bull was approximately ten years older than most of the rest of the Phinda bulls, he dominated the other bulls, remaining in musth for long, continuous periods with abnormal displays of aggressive musth behaviour towards other bulls and humans (Druce et al. 2006). This was possibly due to the absence of competition or conflict with peers or older bulls. As a result, it was decided to introduce three older bulls to create a more natural age structure 
within the male population, by filling the age gap of bulls older than 25 years. It was expected they would have an influence on the behavioural, social and spatial ecology of the resident population. According to previous studies (Slotow \& Van Dyk 2004), African elephants are sensitive to changes in their social structure.

The aims of this study were to determine (1) the effect of the introduction of three older elephant bulls on a young resident bull populations' spatial ecology, by comparing ranging patterns for selected bulls before, during and after the introduction of new bulls; and (2) how the three new bulls settled into the reserve, by determining their ranging patterns immediately after release and comparing them to those of the resident bulls.

\section{Methods}

This study was undertaken in Phinda Private Game Reserve, KwaZulu-Natal, South Africa (27051'30"S, $32^{\circ} 19^{\prime} 00^{\prime \prime E)}$ between March 2003 and June 2004. Both the Forest and Savanna biomes are represented within Phinda. The vegetation type within the Forest Biome at Phinda is Sand Forest (Low \& Rebelo 1996, Type 3), while the Savanna Biome within Phinda is described by three vegetation types; Sweet Lowveld Bushveld (Low \& Rebelo 1996, Type 20), Natal Lowveld Bushveld (Low \& Rebelo 1996, Type 26) and Coastal Bushveld-Grassland (Low \& Rebelo 1996, Type 23). Phinda has a summer rainfall regime and temperatures range from a minimum of $10^{\circ} \mathrm{C}$ in winter to a maximum of $35^{\circ} \mathrm{C}$ in summer. One perennial river, the Mzinene River, flows from west to east through the southern section of Phinda. During the rainy season, surface water is extensive and during the dry periods, six dams, distributed throughout the property, are supplied with borehole water.

\section{Bull introductions and monitoring}

The first two bulls-PH32 aged 29, and PH33 aged 36 - were introduced into the electrified Phinda holding boma on 12 July 2003 . These bulls remained in the boma until their release on 14 July 2003. A third bull-PH31 aged 41 - was introduced into the boma on 1 August 2003 and broke out on the evening of 2 August 2003. On the evening of 3 August 2003 he broke out of the reserve though an un-electrified gate. The following day he was recaptured, using immobilisation, and returned to the boma for a fur- ther four days before his release into the reserve on 8 August 2003. Before his second release, all gates were electrified and no elephants have since broken out of the reserve.

All independent adult male and adult female elephants on Phinda were identified through unique ear patterns, tusk size and shape as well as any other body characteristics. Identity templates were drawn for each individual elephant, including the three older introduced bulls. Two of these introduced bulls were fitted with GPS collars. These collars download GPS positions at set time intervals and transmit the GPS points to a ground station using GSM cell-phones. The collars were set to download location points every two hours, which were then stored on a master computer.

The Phinda elephant population was monitored daily from a vehicle and at each sighting all elephants were identified using the master identification file. At every sighting, date, time, vehicle GPS location, animal distance and bearing from the vehicle, total group size, number of males, females and young, habitat type, name of adult individuals present and behaviour codes were recorded. Most observations were made from a vehicle on the existing road network, due to the difficulty of driving off road in dense woodland, especially in the north of Phinda. With the extensive road network on the reserve, observations was regarded as being sufficient, with a total of 347 sightings for all five resident bulls for the duration of this study period. However, with only two bulls being collared, and located at will, some individual bulls may not have been seen for extended periods. The maximum period that an individual bull was not located was 29 days, but on average, the period between consecutive sightings for an uncollared bull was 3.9 days.

\section{Ranging patterns}

In order to determine if the introduction of the three older bulls had any effect on the resident bulls' ranging patterns, sightings data for the five resident bulls most frequently seen-PH1 age 36, PH2 age 26, PH4 age 26, PH6 age 24, and PH16 age 19-were compared with that of the two collared, introduced bulls (PH31 and PH32). For this study, location data from 1 April 2003 to 30 June 2004 were used. Three time periods were selected for each individual bull, correlating with three months before the bull introduction (1 April to 30 June 2003), three months after the older bull introduction (1 August to 31 October 2003), and 9-12 months after the older bull introduction (1 April to 30 June 2004). As there may have been a number of locations recorded for a bull on a 

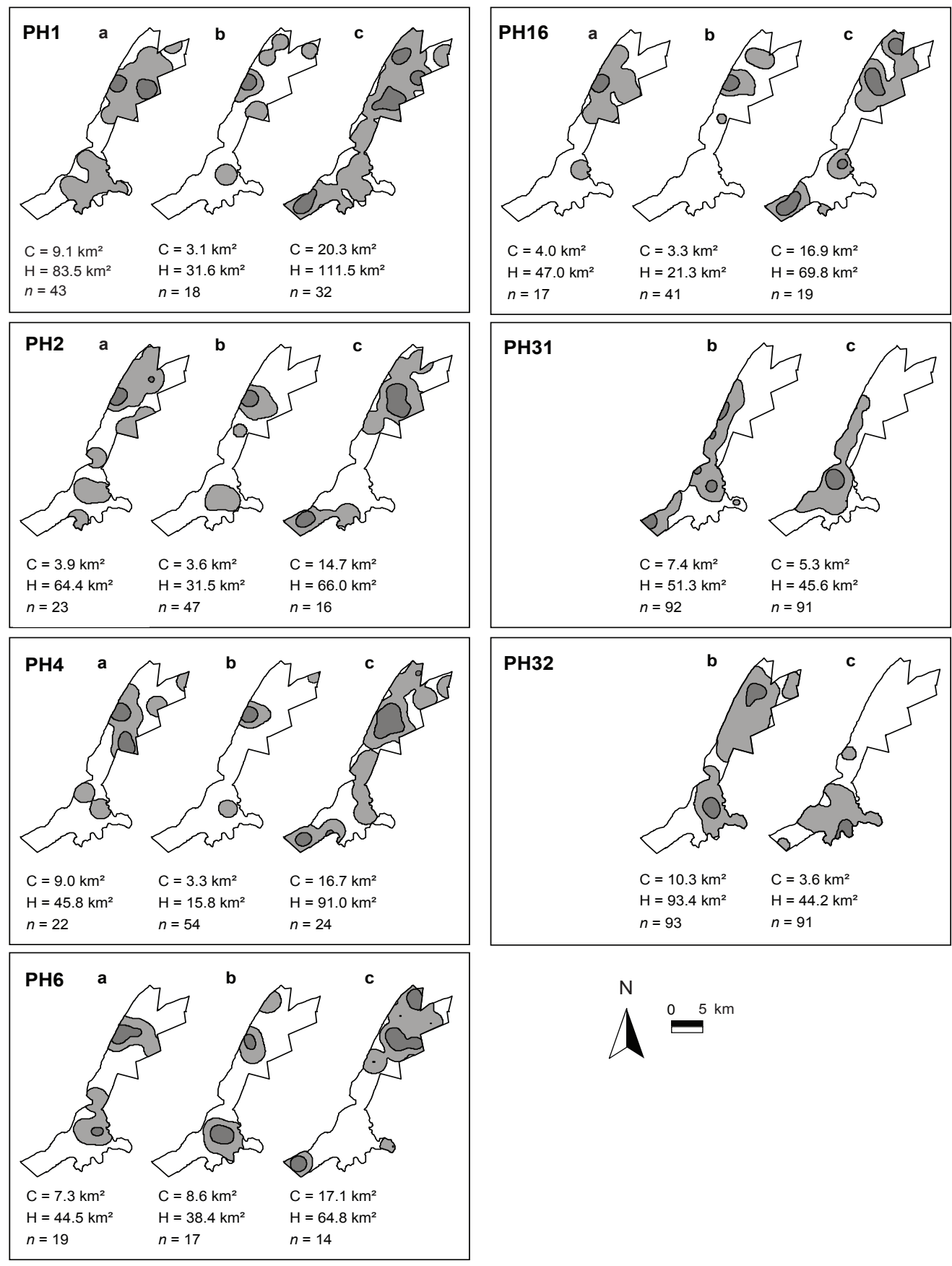

Fig. 2. Ranging of bull elephants on Phinda: The effect of the introduction of older elephant bulls on the ranging behaviour of younger, resident bulls. Three maps are shown for each resident bull and two for the introduced bulls: (a) three months before the introduction of the new bulls, (b) three months directly after introduction, (c) three month period 9-12 months after introduction. $\mathrm{C}=$ Core ranges $(50 \%$ kernel - dark grey shading) and $\mathrm{H}=$ home ranges (95\% kernel - light grey shading). $n$ = number of sightings used to calculate ranges for that period. 
particular day, only the first location after 06:00 each day for individual bulls was used in the analysis. The three-month period one year after the bull introduction was used in the analysis as it correlated with the same season as the previous year immediately before introduction. As a result, any confounding factor of season on bull ranging patterns could be accounted for.

The period from June to October 2003 fell within an extremely dry winter, during which a combination of lucerne, Eragrostis grass and sugarcane tops were provided at 10 waterholes and at the airstrip on the reserve (Fig. 1). All the artificially provided food resources were positioned at water points. We assumed that the elephants would concentrate at or near these water sources due to the drought, with the result that the addition of artificial food would not have an influence on their movement patterns and corresponding home ranges.

Before analysis, the data set was checked for possible errors or duplicate records. Each sighting record was checked on a master spreadsheet against the map for accuracy, with any outlying GPS points or sightings that did not match the road name description being corrected and/or deleted. Data were processed in Microsoft Excel and imported to ArcView 3.2 (ESRI). The Animal Movement Analysis ArcView extension (Hooge \& Eichenlaub 1997) was used in all GIS analyses to estimate the ranges, with the $95 \%$ kernel being used as the estimate of home range and the $50 \%$ kernel as an estimate of core range (Burt 1943; Worton 1989; Seaman \& Powell 1996). A Least Squares Cross-Validation (LSCV) smoothing factor of $1000 \mathrm{~m}$ was used throughout all GIS analyses. Separate maps were produced for the various three-month periods for each individual bull.

The core and home ranges of individuals were compared between the three month period before introduction and three months directly after introduction, as well as between the three months before introduction with the same three month period one year later. Only ranges produced from more than 14 sightings were used in the statistical analysis. Seaman et al. (1999) state that kernel home ranges constructed with less than 30 points result in larger home range estimates. However, for our data, there was no significant effect of sample size on home range size (Linear Regression: $F_{1.17}=0.16, p=0.96$. Data normal: $\mathrm{K}-\mathrm{S}: p=0.695)$. We also confirmed no significant non-linear relationships. Therefore the kernel analysis was used in this study as a comparison to assess influences specific to this study site and population over this time period. All sample sizes are presented with the ranges to allow readers to make independent assessments of the interpretations, and interpretations are cautious as sample size was relatively small. Percentage overlap in ranges were calculated by overlaying maps of the prior three month period with maps of the later three month period and then dividing the area of overlap by the prior area (multiplied by 100), to give a percentage overlap area.

\section{Results}

Overall, the home ranges of the five resident bulls were concentrated mainly in the north of the reserve (Fig. 2), although they also utilised the central areas in the south. During the months immediately after the introduction of the three bulls, the home ranges of resident bulls became much smaller and concentrated around water sources.

During the three months prior to the introduction of the new bulls and a year after the introduction, PH1, the oldest resident bull, had a large home range (Fig. 2) that covered a large proportion of the reserve. For the three-month period after the introduction of the older bulls (Fig. 2), his home range included areas in the north and south. During all three of these study time periods, PH1 spent an average of 39 days in musth, while for the period immediately after the introduction, PH1 was only in musth for 19 days (Druce et al. 2006). This may explain why his home ranges differed in size and distribution from that observed for both the other three-month periods, when he was in musth for almost the entire period. During musth periods, PH1 was mainly seen following breeding herds which tended to move throughout the reserve and have large home ranges (unpublished data). During times when PH1 was not in musth, he was on his own and did not follow herds.

The resident bulls decreased their home ranges $(95 \%$ kernel) significantly immediately after the introduction of the older bulls (Wilcoxon Signed Ranks, $T=-2.023$, $n=5, p=0.043$, Table 1). All core $(50 \%$ kernel) ranges, with the exception of PH6, decreased following the introduction of the older bulls, although this was not significant (Wilcoxon Signed Ranks, $T=-1.214, n=5$, 
Table 1

Effect of bull introductions on ranging patterns of resident bulls and changes in ranging patterns of introduced bulls

\begin{tabular}{lcccccccc}
\hline & $\begin{array}{c}\text { \% overlap of range } \\
\text { 3 months after intro- } \\
\text { duction with range 3 } \\
\text { months before intro- } \\
\text { duction }\end{array}$ & Range change & \multicolumn{3}{c}{$\begin{array}{c}\text { \% overlap of range } \\
\text { 9-12 months after } \\
\text { introduction with } \\
\text { range 3 months before } \\
\text { introduction }\end{array}$} & Range change \\
\hline Bull & Core $^{\text {a }}$ & Home & Core & Home & Core & Home & Core & Home \\
\hline PH1 & 33 & 28 & Decreased & Decreased & 6 & 81 & Increased & Increased \\
PH2 & 75 & 31 & Decreased & Decreased & 14 & 54 & Increased & Increased \\
PH4 & 31 & 33 & Decreased & Decreased & 44 & 75 & Increased & Increased \\
PH6 & 36 & 46 & Increased & Decreased & 35 & 43 & Increased & Increased \\
PH16 & 83 & 35 & Decreased & Decreased & 30 & 68 & Increased & Increased \\
\hline
\end{tabular}

a Core $=50 \%$ kernel

bHome $=95 \%$ kernel

$p=0.225)$. There was a significant increase in both core ranges (Wilcoxon Signed Ranks, $T=-2.02, n=5, p=0.043$ ) and home ranges (Wilcoxon Signed Ranks, $T=-2.02, n=5$, $p=0.043$ ) between the three-month period before the bull introductions with the three month period 9-12 months later (Table 1). We assessed range shift by contrasting overlap of ranges relative to the period before the introduction. There was no significant difference in the overlap of the home (Wilcoxon Signed ranks: $T=-0.674, n=5, p=$ $0.50)$ or core $(T=-1.753, n=5, p=0.080)$ ranges in the three months after introduction vs 9-12 months after introduction (Table 1). This implies that the resident males did not shift their ranges in response to the introduction of the older bulls.

The two introduced bulls utilised areas on the reserve not frequently utilised by the resident bulls. The oldest bull, PH31, patrolled the western boundary for the duration of the first three months (Fig. 2). The second introduced bull, PH32, had a home range covering most of the reserve during the three-month periods after introduction (Fig. 2). During the first three months after introduction, PH32 had two core ranges, one in the north and the other in the south. A year later, his core range had shifted to the far southern corner of the reserve (unpublished data). The third uncollared introduced bull (PH33) was not used in this analysis, but observational data shows that he associated closely with PH31, the oldest introduced bull (unpublished data). Although these two bulls were introduced on different dates into the reserve, they joined up to form a bull coalition and were only seen apart during each other's musth periods.

\section{Discussion}

With the exception of Pilanesberg National Park (Slotow et al. 2000; Slotow \& Van Dyk 2001; Dickerson 2004; Slotow \& Van Dyk 2004), no studies have been done in small, enclosed reserves to determine the effect and success of older bull introductions into established elephant populations. This study was, therefore, important to determine the success of the introduction of the older bulls to Phinda, their effect on the ranging patterns of the resident bulls and to allow comparison with the only other similar study that had been previously undertaken.

The decrease in the resident bulls home ranges during the three-month period immediately after the introduction, may be due to a seasonal influence rather than the introduction per se. The home ranges of resident bulls were concentrated around water resources for 
this three-month period as it fell within an extremely dry winter. The newly introduced bulls showed larger home ranges during this three-month period immediately after their release. These larger home ranges can possibly be explained as exploration of their new area (similar to findings in Pilanesberg: Slotow \& Van Dyk 2004). However, it is interesting that the core ranges for the older introduced bulls during the three-month period immediately after introduction was also concentrated around water sources. The resident bulls knowledge of local resource distribution might have been a reason why they did not link up with the older bulls during the introduction period.

Seasonal factors surely seemed to have affected the resident bulls home ranges more than the introduction of the older bulls. Interestingly enough, all the resident bulls avoided the older introduced bulls' core ranges completely and showed only a small overlap with introduced bulls' home ranges. Therefore, the introduction of the older bulls could have influenced the resident bulls in that they avoided the older new bulls. However, the older introduced bulls may also have used spatially separate areas to other elephants, in setting up independent bull areas away from the female family groups.

The older bulls successfully managed to establish themselves into the population. The introduction helped in normalising the age structure (Slotow et al. 2005), although some of the younger bulls will still need to be removed in order to produce a more normal bull population. In Phinda the resident bull population has remained unchanged until present, although in Pilanesberg, all the problem animals were removed from the reserve (Slotow et al. 2000; Dickerson 2004). All the introduced bulls in Pilanesberg were older than the resident bull population, while in Phinda only one introduced bull was older than the oldest resident bull. Both these factors appear to have contributed to Pilanesberg's immediate success. The introduction of older bulls into Phinda resulted in no major disruptions to the resident bull behaviour, with only subtle effects on the resident bulls' ranging patterns. The resident bulls' ranging changes responded more to ecological factors than to the influence of the mature bull introduction. These results, in combination with those from the Pilanesberg introduction (Slotow \& Van Dyk 2004), indicate that the introduction of older male elephants into small populations does not pose major risks or animal welfare concerns.

\section{Acknowledgements}

This study was funded by a donation from Distell (Pty) Ltd to the Amarula Elephant Research Programme, University of KwaZulu-Natal and by the Conservation Internship Programme of the Wildlands Conservation Trust. A special thanks to all the interns who helped with data collection. CCAfrica, Phinda Private Game Reserve provided accommodation and logistical support, while Clive and Allan are thanked for maintaining the research vehicle. This work forms part of an NRF grant (GUN number 2053623) to RS.

\section{References}

BURT, W.H. 1943. Territoriality and home range concepts as applied to mammals. Journal of Mammalogy 24: 346-352.

Dickerson, T. 2004. The effect of older elephant bull introduction on resident young orphan bull social dynamics: Pilanesberg National Park. BSc Hons thesis, University of KwaZulu-Natal, Durban.

Douglas-Hamilton, I. 1973. On the ecology and behaviour of the Manyara elephants. East African Wildlife Journal 11: 401-403.

Druce, D., H. Genis, J. Braak, S. Greatwood, A. Delsink, R. Kettles, L. Hunter \& R. Slotow. 2004. Population demography and spatial ecology of a reintroduced lion population in the Greater Makalali Conservancy, South Africa. Koedoe 47(1): 103-118.

Druce, H., K. Pretorius, D. Druce \& R. Slotow. 2006 (in press). The effect of mature elephant bull introduction on resident bull's group size and musth periods: Phinda Private Game Reserve. South African Journal of Wildlife Research 36(2).

Garaï, M.E., R. Slotow, R.D. CARr \& B. Reilly. 2004. Elephant reintroductions to small fenced reserves South Africa. Pachyderm 37: 28-36.

Hooge, P.N. \& B. Eichlenlaub. 1997. Animal movement extension to ArcView version 1.1. Alaska Biological Science Center. Anchorage: U.S. Geological Survey. 
LAWS, R.M. \& I.S.C. PARKER. 1968. Recent studies on elephant populations in East Africa. Symposia of the Zoological Society of London. 21: 319-359.

Low, A.B. \& A.G. Rebelo (eds.). 1996. Vegetation of South Africa, Lesotho and Swaziland. Pretoria: Department of Environmental Affairs and Tourism.

Moss, C.J., \& J.H. Poole. 1983. Relationship and social structure in African elephants. Pp. 315325. In: R.A. HindE (ed.). Primate social relationships: An intergrated approach. Oxford: Blackwell.

Poole, J.H. 1989. Announcing intent: the aggressive state of musth in African elephant. Animal Behaviour 37: 140-152.

Poole, J.H., L.H. Kasman, E.C. Ramsay \& B.L. LASLEY. 1984. Musth and urinary testosterone concentrations in the African elephant (Loxodonta africana). Journal of Reproduction and Fertility 70: 255-260.

SeAman, D.R. \& R.A. Powell. 1996. An evaluation of the accuracy of kernel density estimators for home range analysis. Ecology 77: 2075-2085.
Seaman, D.R., J.J. Millspaugh, B.J. Kernohan, G.C. BRundige, K.J. RaedeKe \& R.A. Gitzen. 1999. Effects of sample size on kernel home range estimates. Journal of Wildlife Management 63: 739-747.

SLOTOW, R. \& G. van Dyk. 2001. Role of delinquent young "orphan" male elephants in high mortality of white rhinoceros in Pilanesberg National Park, South Africa. Koedoe 44(1): 85-94.

SLOTOW, R. \& G. VAN DYK. 2004. Ranging of older elephants introduced to an existing small population without older males: Pilanesberg National Park. Koedoe 47(2): 91-104.

Slotow, R., G. van Dyk, J.H. Poole, B. Page \& A. KLOCKE. 2000. Older bull elephants control young males. Nature 408: 425-426.

Slotow, R., M.E. Garaï, B. Reilly, B. Page \& R.D. CARR. 2005. Population dynamics of elephants re-introduction to small fenced reserves in South Africa. South African Journal of Wildlife Research 35: 23-32.

WorTON, B.J. 1989. Kernel methods for estimating the utilization distribution in home-range studies. Ecology 70: 164-168. 